\title{
Transtornos mentais e trabalho: o caso de um agente de visitação
}

\author{
Carlos Eduardo Carrusca Vieira ${ }^{\mathrm{I}, 1}$ e Rosemary Carrusca Vieira ${ }^{\mathrm{II}, 2}$ \\ ${ }^{\text {I }}$ Pontifícia Universidade Católica de Minas Gerais \\ II Prefeitura Municipal de Belo Horizonte
}

\begin{abstract}
O estabelecimento do nexo causal entre trabalho e distúrbio mental tem ocupado um lugar central nos debates teóricos e se configura como uma questão bastante polêmica, centro de controvérsias no campo de estudos da Saúde Mental e Trabalho. O presente artigo discute o caso de um trabalhador cujo processo de adoecimento parece estar relacionado à sua última experiência de trabalho. A construção deste caso foi inspirada no método biográfico de Louis Le Guillant (2006) e na Análise Psicossocial do Trabalho proposta por Lima (2002). Os dados empíricos foram coletados por meio de cinco entrevistas não-estruturadas, realizadas junto ao trabalhador. No decorrer do estudo, também foram analisados os laudos emitidos pelo serviço de perícia médica da instituição contratante. Ao final deste artigo, indicamos que as agressões sofridas no trabalho, a precariedade do suporte social para a resolução dos conflitos, a degradação da ação profissional e do sentido do trabalho, a ausência de reconhecimento e as escalas de folga incompatíveis com a preservação da vida social do trabalhador se configuram como elementos-chave para $o$ entendimento do processo de adoecimento.
\end{abstract}

Palavras-chave: Saúde do trabalhador, Transtornos mentais, Psicologia do trabalho.

Mental disorders and work: the case of an agent visits

Establishing a causal relationship between work and mental illnesses has been at the center of theoretical debates and considered a rather polemic issue, being one of the controversies in the field of mental health and work. This article discusses the case of a worker whose process of getting sick seems to be connected to his last work experience. The groundwork of this case was the Biographic Method of Louis Guillant (2006), and the analysis of work-related psychosocial factors proposed by Lima (2002). The data were found empirically by means of carrying out five unstructured interviews with the worker. Over the studying period, the report issued by the medical inspection service of our client was also analyzed. In the end of this article, we indicate the aggressions and aggravations suffered by the worker such as an insufficient social support for solving conflicts, the degradation of the professional activity, and as well of the meaning of work itself, the lack of acknowledgment, and also work-rest shift schedules unfitted for allowing the worker to preserve his social life are the main factors that proved to be the key-elements for understanding such sickening process.

Keywords: Occupational health, Mental disorders, Work psychology.

\section{Introdução}

$\mathrm{O}$ presente artigo analisa o caso de um trabalhador cujo processo de adoecimento apresenta uma estreita relação com a sua última experiência de trabalho. Trata-se do caso de um agente de visitação, empregado pela Fundação de Parques de Belo Horizonte (nome fictício).

Admitido em 2008 para o cargo, Thales (nome fictício) deveria desempenhar funções como: realizar e apoiar atividades educativas junto ao público, tais como visitas monitoradas, mobilizações, oficinas, oferecer informações adequadas sobre os animais, plantas e funcionamento das diversas áreas que compõem a Fundação de Parques, entre outras funções. Entretanto, seus relatos indicam que, em vez de desempenhar essas funções, ele realizava

1 Psicólogo. Doutorando e Mestre em Psicologia pela Universidade Federal de Minas Gerais. Professor na Pontifícia Universidade Católica de Minas Gerais. Coordenador da área de Psicologia do Trabalho e Organizações (PTO) da PUC Minas São Gabriel. 
tarefas pertencentes ao universo dos serviços de vigilância, como relatou logo na primeira entrevista: "Eu fiz concurso pra ser educador ambiental. Triste ilusão. Lá a gente era vigia".

As experiências de trabalho vividas no parque como "vigia" parecem ter impregnado a sua vida de um forte sentimento de tristeza, revolta e inutilidade, deteriorando por fim a sua saúde, motivo pelo qual foi afastado da função, com o diagnóstico de "Transtorno misto ansioso e depressivo" (CID-10: F.41-2) e "Reações ao estresse grave e transtornos de adaptação" (CID10: F.43), pelo serviço de perícia médica de sua empresa.

A construção deste caso foi inspirada no método biográfico de Louis Le Guillant (2006) e na Análise Psicossocial do Trabalho, apresentada por Lima (2002), que propõem o resgate e a análise minuciosa da trajetória biográfica do indivíduo, de seus modos de julgar e conduzir a vida, de seu sistema de valores e da representação de mundo forjada por sua história, bem como das condições de vida e trabalho (Le Guillant, 2006). Desse modo, pretendeu-se analisar a trajetória de vida do indivíduo, articulando os dados objetivos, subjetivos e fatos clínicos, visando à compreensão dos fatores relacionados ao processo de adoecimento.

Entretanto, vale ressaltar que, embora nossa pretensão fosse a de analisar a trajetória de vida e as ocupações pregressas do trabalhador, o que teria contribuído para tornar nossas análises mais profundas e precisas, isso não foi possível devido ao pedido de exoneração feito pelo trabalhador. De qualquer forma, acreditamos que os depoimentos de Thales acerca do último emprego, aqui transcritos e analisados, já permitem propor uma discussão da relação entre distúrbio mental e trabalho.

Ao todo, foram realizadas cinco entrevistas não-estruturadas junto ao trabalhador, com a duração média de uma hora e meia cada. Optou-se pela utilização de entrevistas nãoestruturadas, por se tratar de uma técnica que visa proporcionar maior liberdade ao entrevistado para abordar assuntos pertinentes a um dado fenômeno, fato ou situação, além de permitir ao pesquisador um aprofundamento das informações que lhe são fornecidas. Além disso, uma das vantagens desse tipo de entrevista é a de viabilizar a investigação dos significados atribuídos pelos entrevistados a certos fatos, situações e/ou comportamentos, numa sequência que não é preestabelecida, mas que atende às "preocupações e ênfases que os entrevistados dão aos assuntos em pauta" (Minayo, 1994, p. 122).

As entrevistas foram gravadas mediante o consentimento do entrevistado e posteriormente transcritas e analisadas. Para a compreensão do caso, foram analisados também os laudos médicos emitidos pelo serviço de perícia médica da empresa contratante, à qual o trabalhador foi submetido.

\section{O Caso de Thales}

Thales é um jovem de 26 anos, formado pela Universidade Federal de Minas Gerais (UFMG), onde se graduou em História. Seu tom de voz é moderado, às vezes suave, e se expressa de forma coerente e lógica. Entretanto, mostra-se exaltado e nervoso quando indagado sobre suas experiências de trabalho, no cargo de agente de visitação. Não por acaso. Embora seja um profundo conhecedor das questões ambientais, engajado na luta contra a degradação do meio ambiente, Thales desempenhava na Fundação de Parques "tarefas de vigilância”, modo que se refere às atividades que realizava durante as sextas-feiras, sábados e domingos:

Dos cinco dias, três são de vigilância e dois são muito bons, incentivando as escolas. É o seguinte: você pega a escola lá embaixo na estação de tratamento, vai falar praquela criança, estudante, o 
que pode fazer pra melhorar isso... água, ficar habitável, fala da dificuldade de tratar a água, a nata da sujeira, ela fica oxigenada e lá no final tem pássaros, jacarés, peixes.

De acordo com seus relatos, seu processo de adoecimento teve início dois meses após ter ingressado no trabalho e parece estar estreitamente relacionado ao exercício da função de vigia, como ele mesmo afirma:

O meu adoecimento começou dois meses depois que eu entrei. Entrei muito feliz... Agora vou ganhar um salário digno... um sonho, uma vitória. (...) Aí começo a trabalhar como vigia, desagradando e não desligava do trabalho. Penso toda hora [nisso]... ouvindo um monte de porcaria, com o sol queimando a pele toda. Tenho uma marca, [porque o trabalho me] marcou até fisicamente. Olho no espelho e lembro do trabalho. Um trabalho extremamente desagradável, fora da sua função. (...) Eu preferia um serviço braçal, que fosse... plantando alguma coisa, trabalhando numa coisa suportável... aí você vai ter dignidade, dinheiro...

[mas trabalhar] o dia inteiro mandando descer pipas? [Era] Trabalho de guarda mesmo, no meio tem bandido, bêbado...

É possível notar que o fato de Thales ter sido obrigado a exercer uma atividade cujo fim é impedir, proibir, advertir e "cortar o barato das pessoas" é um dos fatores que lhe acarretaram muitos sentimentos negativos e problemas na vida amorosa:

O que se faz na sexta-feira e fim de semana se aproxima da atividade de vigilância, inchui ação de coerção, repressão... [Pedir para as pessoas] Descer de árvores, não jogar bola em jardim, verificar se tem ou não cerol nas pipas... em julho é inferno. [...] o trabalho é uma porcaria... [tenho que ficar] chamando a atenção dos outros... não pude levar o namoro adiante.

Fico muito feliz quando eu posso ajudar. Mas quando a regra é estúpida é mais difícil você seguir. O cara [usuário do parque] tá feliz e você tem que cortar o barato do cara. E as pessoas pensam que você sente prazer com aquilo. Eles falam: "Aí ó... põem o poder na mão do cara, dá nisso aí...". Pra mim isso é a morte! Quero que o sujeito fique numa boa, eu gosto de ver as pessoas felizes.

Não fiz concurso pra isso [ser vigia], mas para educar e encantar as pessoas com a carreira ambiental para que não comprem um casaco de pele... (...) Ninguém fez concurso, ninguém tem ethos pra isso [vigilância]. Tem gente que tem ethos pra educador...

Além de desempenhar uma função incompatível com os seus anseios e para a qual não foi treinado, Thales tinha de lidar também com a resistência às normas e as agressões por parte do público que frequentava o parque, elementos relacionados ao seu sofrimento no trabalho:

[...] a gente tem que fechar o parque... [Aí] Eu fui conversar com um sujeito bêbado, ele falou um monte de esporro e chamou nosso colega de viado, e aí fugiu antes da polícia chegar [...] Palavrão é "mato"! Acontece direto, acontece muito. "Seu filho da puta, seu merda!".

No nível de [falar] filho da puta, seu merda, esse nível é uma vez no mês olhando no seu olho. Mas isso de falar e virar as costas e falar e ir andando é direto! Olhando no olho é afronta mais ainda. E você não pode afrontar.

As condições de trabalho também não eram "boas", de acordo com Thales, pois não tinha assentos adequados e permanecia exposto ao sol por longos períodos:

Aquele banquinho é uma bosta... (referindo-se ao banco oferecido aos agentes de visitação)... minha gerente foi muito bacana de deixar eu trazer o meu, permitiu que eu levasse o meu, que é ergonômico, é de plástico, não causa dano a mim....tem encosto pro braço e costas e nunca mais tive problemas de coluna.

...o sol [é] que atrapalha, é muito forte mesmo. 
Ninguém usava guarda-sol (...), se fossem CLT teriam que receber insalubridade...

Em outros momentos de sua trajetória ocupacional, Thales lembra-se de ter se sentido mais satisfeito com o trabalho, pois encontrava nele a possibilidade de encantar as pessoas por meio da atividade de educação ambiental. Sentia-se bem por poder agir e ser reconhecido:

O agradecimento... os mais velhos [diziam] "Deus te abençoe". Sou um sujeito muito carinhoso. Eu explicava bem devagarinho pra eles [idosos]. Eu ganhava beijos, [de] muitas vovós. Não existiam motivos pra conflitos. [No parque] Dia de semana é mais ou menos o mesmo tratamento. E gosto de fazer as coisas relativamente bem feito. Direto chega gente falando: "Thales tem uma didática muito boa!".

Entretanto, no cargo de agente de visitação, mas desempenhando atividades de "vigia", Thales sentia-se "torturado". Atualmente, afastado do trabalho e tendo de tomar medicamentos com "tarja preta", "coisa que nunca imaginava que ia ter que fazer", ele expressa ansiedade e preocupação quando imagina a possibilidade de ter de retornar ao trabalho:

Eu tive uma crise nervosa só de pensar em voltar... voltar pro inferno. Mandar o pessoal descer de árvore, xingar sem poder retrucar. Vários dos meus colegas tiveram que fazer B.O. [Boletim de Ocorrência]. Você trabalha com o "não" e não com o "encantar", "educar". Agora tem que tomar pipa dos sitiantes! (...) Eles estão me torturando. Tortura a mente, é uma coisa que existe...

Ressalte-se que Thales relata ter percebido importantes mudanças no comportamento e humor dos colegas, em função das tarefas de vigilância que desempenhavam:

...estão acabando com o sonho dessas pessoas (colegas de trabalho), tirando o convívio social da família. Você não fez o concurso pra isso! E todos lá, de uma forma ou de outra, sofrem danos emocionais com o trabalho, uns ficam mais agressivos. Eram amáveis e hoje é difícil de conviver.

\section{O processo de adoecimento e as avaliações psiquiátricas}

No quinto mês de trabalho, Thales teve de ser afastado de suas funções por três dias, o que foi documentado nos registros da perícia médica apresentados pelo trabalhador, da seguinte forma:

Informa ter apresentado quadro de dor no ouvido direito, associado a um quadro gripal. Fez limpeza de ouvido, ainda com queixa de hipoacusia e dor ao som de ruídos. Fez uso de citriz tópico [sic] e medicação para dor, mas não usou, porque disse estar tendo azia e náusea, devido ao uso de antidepressivo (Donarem, $10 \mathrm{mg}$, e Diazepam, $10 \mathrm{mg}$ ), iniciados há duas/três semanas [sic]. Diz estar andando ansioso, devido à indefinição profissional, relacionada a trabalhos extras em finais de semana e feriados. Diz ser formado em História, relata término de namoro recente, que também o afligiu. Alerta, BEG (Bem-estar geral), orientado, eupineico, voz anasalada. CID: J-03.9 (Amigdalite aguda não especificada) ${ }^{3}$.

Thales já se encontrava desgastado com o trabalho e seu namoro não suportou a frequência de suas ausências aos fins de semana. Sendo obrigado a dormir cedo para se refazer e trabalhar no dia seguinte, ele raramente podia preservar suas atividades sociais e de lazer: "A

3 O laudo pericial pode dar a impressão de que o término do namoro, em período recente, é responsável pelo surgimento dos sintomas relatados. Entretanto, como o leitor poderá verificar adiante, são as queixas referentes ao trabalho aquelas que são percebidas como determinantes de seu sofrimento. 
existência fica pobre quando perde o fim de semana". Em um dos dias em que estava trabalhando no parque, sozinho, Thales sentiu todo o peso das situações e contradições que vivenciava: "No dia do aniversário da minha mãe, 21 de abril... Tava na esplanada, com mil e quinhentas pessoas, eu sentei e desisti".

Nesse dia, após ter vivenciado mais desgastes com usuários, Thales parece ter "jogado a toalh ${ }^{\prime \prime}$. Contrariado pela impossibilidade de se realizar e de ser reconhecido, agindo no mundo de acordo com seus valores e saberes, Thales se viu em uma situação difícil: viver o "trabalho insuportável" ou ficar "desempregado", sentindo-se um "inútil". Uma difícil escolha para ele, já que o trabalho em sua vida preenche uma função psicológica importante, relacionada ao processo de autoconstrução, como ele próprio afirma: "Porque pra mim trabalho é também dignidade. O sujeito perde a dignidade quando perde o trabalho. Tenho 26 anos, porra! Você perde o poder de ser dono de você mesmo".

Logo após a situação, o trabalhador solicitou atendimento à perícia médica e teve de ser afastado novamente, dessa vez por um período de nove dias, em razão de um "transtorno misto ansioso e depressivo" (CID-10: F.41-2), conforme registrado no relatório da perita:

Licenciado devido quadro de depressão, bruxismo e cefaleia. Insatisfeito com as atividades que está executando (trabalha todo final de semana, alega que fez curso superior e não mexe com educação ambiental). Sentindo-se como um guarda de patrimônio; gosta de dar aulas, ensinar. Em uso de Donarem 100 mg e Diazepam (S.N.). CID: F.41-2. Apático e humor deprimido.

A terceira licença veio logo após o término da anterior e demonstra, claramente, uma evolução dos problemas de saúde e sua relação com as tarefas de vigilância que realizava no parque. Aliás, dessa vez, Thales foi atendido por uma psicóloga do setor de perícia médica e, devido à gravidade do caso, foi encaminhado também a uma psiquiatra. $\mathrm{O}$ trabalhador foi afastado pela médica por um mês, com a indicação diagnóstica de "transtorno misto ansioso e depressivo" e "reações ao estresse grave e transtornos de adaptação", como consta no relatório pericial:

Vem enfrentando problemas no local de trabalho, queixando-se de falta de apoio na execução de suas tarefas ("gostaria de ser educador, e não guarda, só para repreender as pessoas, recebendo xingamentos"). Trabalha todos os sábados e domingos, com folga obrigatória na segunda. Durante a semana, trabalha mais com escolas, o que é gratificante, já que tem oportunidade de passar conhecimentos de educação ambiental. Nos fins de semana, tem que atuar mais na vigilância, o que é difícil para o servidor, que pensa até em pedir demissão. Uso de Trazodone, $50 \mathrm{mg} /$ dia. Queixa-se de ansiedade, angústia, dores difusas pelo corpo, sono irregular. Ansioso, humor eutímico, não expressão sintomatologia produtiva. (Solicito visita ao local de trabalho). (CID: F-43, reações ao estresse grave e transtornos de adaptação e F-41.9, transtorno ansioso não especificado).

O último atendimento do servidor foi realizado três dias antes do vencimento da licença anterior. O próprio Thales relatou se sentir muito ansioso quando o prazo da licença médica se aproxima do fim, o que o faz relembrar as experiências "infernais" que viveu no trabalho. Nessa última ocasião, inclusive, afirmou ter se sentido tão tenso que teve "uma contratura nas costas". O laudo da perícia médica nos informa sobre as possíveis razões do sofrimento e dos transtornos psíquicos apresentados pelo trabalhador:

Relata que as condições de trabalho continuam ruins. Diz que as atividades desenvolvidas

4 É relevante notar que a crise subjetiva ocorreu numa terça-feira, quando supostamente o agente de visitação desempenhava atividades de educação ambiental. Entretanto, essa não era a única atividade que realizava durante semana, pois tinha que cuidar também do bicicletário, alugando as bicicletas do parque para o público em geral. Nessas ocasiões, com frequência havia conflitos entre os agentes de visitação e os usuários do parque, em função das normas de locação das bicicletas. 
nos finais de semana não condizem com a sua função e a escala de revezamento não tem sido efetivamente realizada. Trabalham sábado e domingo (dois finais de semana e folgam um). Diz que o clima geral do setor é de insatisfação, diz que já conversaram, a diretora foi mais sensível, porém o presidente não aprovou a proposta (de escala de trabalho). Relata que não é doente, mas está se sentindo doente, iniciando o uso de antidepressivo, que nunca fez antes. Diz que não se sente em condições de trabalhar, apresentando hiporexia, emagrecendo. Relata que os conflitos entre os servidores e os visitantes têm sido constantes nos trabalhos de fins de semana e feriados. Oriento agendar avaliação com a psiquiatria da perícia médica. Programada visita ao local de trabalho e discussão com outros servidores do setor. Discurso orientado, sem alteração de humor detectada, faciez atípica. Licença: 08/06 a 22/06. CID: F41.1. Ansiedade generalizada.

Os períodos de afastamento do trabalho e a assistência da equipe do setor de saúde e medicina do trabalho parecem ter sido importantes para que o trabalhador fosse capaz de suportar os dramas que vivenciara no trabalho e se recuperasse. Quando indagado sobre como se sentia quando estava de licença médica, Thales afirma que se sentia "voltando a viver no fim de semana":

O fim de semana que tem folga, estava desentrosado de sociedade. Eu sou rico? Não sou. Por ter que me virar com as minhas reservas, arrumar um subemprego. Lutei anos, estudei firmemente pra tá resolvido na minha vida. Estaria errado se faltasse direto, chegasse atrasado. Eles é que estão errados de me obrigar a um trabalho. Excesso de poder discricionário deles. Me adoeceu e me deixa puto.

O afastamento possibilitou também que Thales restabelecesse o seu convívio social, o que ele relata da seguinte forma: “...eu voltei a viver no último mês... suicídio é abominável. Agora todo dia que abro o Orkut [rede de relacionamento por internet] tem gente. Antes não tinha ninguém. Tive possibilidade de ter namorada de novo".

\section{Discussão do caso: as relações entre o trabalho e distúrbio mental}

Como atividade própria do ser humano, pela qual lhe é possível aplicar suas forças e inteligência na transformação da natureza, visando à produção de coisas úteis à sua vida (Marx, 1983), o trabalho é concebido aqui como o balizador da construção de uma sociedade e, em uma perspectiva psicossocial, vital para a compreensão das formas de sociabilidade, identidade (Jacques, 1997), desenvolvimento pessoal e processos de saúde/doença (Clot, 2006; Le Guillant, 2006; Lima, 2008).

Uma análise atenta do caso desse agente de visitação evidencia o peso das experiências de trabalho na determinação do desenvolvimento, dos processos de construção identitária, da autoestima e da saúde/doença. Trabalhar pode constituir-se em uma experiência que ultrapassa $\mathrm{o}$ ato de produzir "coisas" e chega a caracterizar-se como uma tentativa ("bem ou malsucedida") de se pôr no mundo e de "eternizar-se". O trabalho, afirma Clot (2006), é portador de uma função psicológica específica, que se realiza pela ruptura que opera entre as "préocupações" pessoais e as ocupações sociais das quais o sujeito tem de se encarregar, o que possibilita a ampliação de seu contato com o universo humano e "sair de si mesmo".

Mas, se, por um lado, o trabalho pode se constituir como um recurso para a saúde, fator integrador e fortalecedor da identidade, por outro, sua ausência, deterioração e forma de organização podem conduzir a experiências patogênicas, como mostram vários estudos no campo da Saúde Mental \& Trabalho (Dorigo \& Lima, 2007; Le Guillant, 2006; Lima, 
Assunção \& Francisco, 2002; Ministério da Saúde, 2001; Vieira, 2009) 5 .

A Psicologia do Trabalho interessa-se, assim, pelo "fazer das pessoas", nesse duplo sentido da expressão e pelo potencial ambíguo do trabalho, de constituir-se como recurso de construção da saúde ou fator que contribui para o adoecimento.

Neste caso, é evidente o potencial patogênico das experiências de trabalho. Em todos os registros feitos pela perícia médica estão presentes queixas quanto ao trabalho, especialmente aquelas que se relacionam ao desvio de função ["ser vigia"], às tarefas que realiza nos finais de semana e aos conflitos com os usuários do parque. O período de conflitos no trabalho deixou marcas profundas na história e na saúde do agente de visitação, talvez um dos motivos pelos quais as queixas em relação ao trabalho ocuparam um lugar de destaque em seus depoimentos.

O "transtorno misto ansioso e depressivo" (CID-10: F.41-2), pelo qual o agente de visitação foi acometido, caracteriza-se, de acordo com a Classificação Internacional de Doenças, pela presença concomitante de "sintomas ansiosos e sintomas depressivos, sem predominância nítida de uns ou de outros, e sem que a intensidade de uns ou de outros seja suficiente para justificar um diagnóstico isolado" (Organização Mundial da Saúde, 1994).

No caso do diagnóstico registrado na categoria de "Reações ao estresse grave e transtornos de adaptação", pressupõe-se que o indivíduo vivenciou um "acontecimento particularmente estressante" capaz de desencadear "uma reação de 'stress' aguda, ou uma alteração particularmente marcante na vida do sujeito, que comporta consequências desagradáveis e duradouras e levam a um transtorno de adaptação" (Organização Mundial da Saúde, 1994).

Em particular, no caso de Thales, é possível perceber que o desvio de função, as agressões e ofensas sofridas no cotidiano de trabalho compõem o núcleo de suas reclamações e queixas. Contudo, certos aspectos do trabalho também podem ser elencados como fatores nocivos à saúde, como, por exemplo: a degradação da ação profissional e do sentido do trabalho (Clot, 2006), a ausência de reconhecimento (Dejours, 2004), a precariedade do suporte social para a resolução dos conflitos e as escalas de folga incompatíveis com a preservação da vida social do trabalhador. A nosso ver, esses são elementos-chave para o entendimento do processo de adoecimento de Thales.

A pouca identificação com o trabalho (de vigia) e a degradação do agir também podem ser indicadas como situações que favoreceram o adoecimento, como é possível perceber em vários relatos feitos pelo trabalhador:

Não tenho natureza pra isso [vigiar]. [...] Escolhi este emprego porque gosto de encantar as pessoas. Me sinto útil quando conscientizo as pessoas. Toda ação você tem que ter essa legitimação da sua ação, para frear essa degradação do mundo.

Essa última transcrição indica que o reconhecimento do trabalho constitui um elemento importante no âmbito da produção de significações, da construção da identidade e manutenção da saúde psíquica (Dejours, 2004). O reconhecimento pode ter um papel relevante na regulação da dinâmica entre prazer/desprazer no trabalho, e a sua ausência pode ser sentida em outras esferas da vida: "Quando o reconhecimento do trabalho não existe, a desvalorização consequentemente atinge outros espaços da vida cotidiana dos trabalhadores, contaminando o tempo do não-trabalho" (Dejours, 2004, p. 33).

5 Aliás, sobre os impactos da ausência do trabalho para a saúde, vale ressaltar que o próprio Ministério da Saúde, no Manual de Procedimentos para os Serviços de Saúde, entende que: "Em decorrência do lugar de destaque que o trabalho ocupa na vida das pessoas, sendo fonte de garantia de subsistência e de posição social, a falta de trabalho ou mesmo a ameaça de perda do emprego geram sofrimento psíquico, pois ameaçam a subsistência e a vida material do trabalhador e de sua família. Ao mesmo tempo, abala o valor subjetivo que a pessoa se atribui, gerando sentimentos de menos-valia, angústia, insegurança, desânimo e desespero, caracterizando quadros ansiosos e depressivos" (Ministério da Saúde, 2001, p. 161). 
O Ministério da Saúde também reconhece o fato de que "(...) o trabalho desprovido de significação, sem suporte social, não-reconhecido ou que se constitua em fonte de ameaça à integridade física e/ou psíquica, pode desencadear sofrimento psíquico" (Ministério da Saúde, 2001, p. 161).

Mas, além disso, o depoimento ora transcrito evidencia que o sofrimento está relacionado também à "amputação do poder de agir" (Clot, 2006). A "desautorização", "deterioração" ou "deslegitimação" da ação profissional podem assim ser sentidas como um ataque à subjetividade, motivo pelo qual "o sofrimento não é unicamente definido pela dor física ou mental, mas também pela diminuição, ou até a destruição da capacidade de agir, do poder fazer, percebida como atentado à integridade de si" (Ricoeur, 1990, citado por Clot, 2007, p. 274).

Desse modo, não apenas a deterioração da dinâmica do reconhecimento, mas também a perda de destinatários da atividade, a degradação do sentido da atividade e do gênero profissional (Clot, 2006) podem ser relacionados à experiência do sofrimento psíquico, por suas implicações para o sujeito trabalhador. $O$ trabalho pode perder seu sentido "quando ele não permite mais a realização das metas vitais e dos valores que o sujeito extrai de todos os domínios da vida em que sua existência está envolvida, inclusive o trabalho" (Clot, 2006, p. 73).

Outro aspecto importante para a compreensão do caso de Thales é a "impossibilidade" de "retrucar" às ofensas do público que frequentava o parque, o que configurou-se como uma situação potencialmente traumática, já identificada em outros estudos (Vieira, 2008). Aqui, é possível dizer que "ter que engolir" as humilhações e ofensas, e não poder agir (Clot, 2008), é um fator psicossocial de risco para a saúde, cuja importância sempre se faz presente no depoimento de trabalhadores de diferentes categorias profissionais.

Mais que isso, Thales sublinha o fato de que, se estivesse em outros contextos, lhe seria possível dar uma resposta diferente às pessoas que o agrediram verbalmente. Ou seja, ele poderia encontrar meios de "defender" a sua saúde. Entretanto, no contexto de trabalho, não se via em condições de confrontar os usuários do parque por várias razões, entre elas o receio de ser vítima de agressões físicas. O receio do trabalhador se justifica, segundo ele, pelas experiências que já viveu em outros momentos:

Eu engulo muitas vezes [essas ofensas] porque já trabalhei em favelas. Eu não sou nenhum cara da "elite", que não conhece essas coisas. Isso ajuda a engolir. Se o cara quiser, ele pode me assassinar dentro do parque e ocultar... o cadáver. Eu não vou ser estúpido para abordar uma galera que tá fumando maconha escondido num lugarzinho lá e que depois eles me pegam e me abordam lá fora.

No parque eu já não tenho vigia perto. Às vezes isso passa na cabeça porque a gente conversa com vigias. Porque o vigia quando sai do banco jamais sai com o mesmo uniforme. E mesmo assim os caras marcam [ele]. Mas eles já têm outro ethos e formação. Eu nunca dei um tiro na vida, não tenho arma. Sou um sujeito normal, professor. Não tenho natureza pra isso [vigiar].

Imagina que tem um pivete ali quebrando a árvore. Aí você fala: Oh meu amigo, não pode mesmo subir na árvore. Aí o cara te olha de lado, meio te jurando muitas vezes.

Podia dar merda se eu xingasse alguém! Um colega meu empurrou um cara da bicicleta e quase foi processado.

Em algumas situações de resistência de usuários às normas do parque, os agentes de visitação chamavam os seguranças, mas nem sempre havia vigilantes para dar suporte à ação dos agentes: "Quando tinha situação de resistência a gente chamava o vigia. Mas tem muitas vezes que estamos sozinhos". 
Indagado a respeito das sensações vividas quando era "obrigado" a engolir as ofensas do público, Thales explicita da seguinte forma essa experiência de "intoxicação emocional":

Imagina você fumar um charuto, ter que dar aquela tragada e não poder soltar, ter que engolir! Aquilo fica preso no seu pulmão. Isso adoece, e eu tô adoecendo... e tem outras pessoas que também tão adoecendo...

A metáfora da intoxicação utilizada por Thales para descrever a relação entre as "intragáveis" agressões sofridas no contexto de trabalho ilustra o potencial patogênico dessas situações para ele.

Ao final de sua trajetória como agente de visitação, Thales havia desenvolvido não apenas o transtorno ansioso e depressivo, mas também um "cacoete", que refletia o seu sofrimento, originado nas experiências de trabalho vividas no parque:

Naquela época, comecei a ter um cacoete, dedo no pescoço [como se puxasse o gatilho de um revólver]... ficar liure da situação de ter que ficar no parque ou ficar jogado aí. [...] Eu comecei a pensar em suicídio, todos os dias, desespero. Porra, eu fiz essa merda de concurso e eu é que vou ter que sair!? Se eu ficar eu tenho certeza de que vou ser infeliz, se eu sair eu vou ficar na dúvida. Mas é melhor a dúvida do que a certeza. Já vou sair numa situação ruim, hoje eu não tenho namorada, muito por causa do trabalho e do tempo. Ela falava que eu não tinha tempo pra ela. Eu falava: "tenho que dormir cedo porque meu trabalho é muito irritante".

[Como era isso do cacoete? Em que você pensava?] De vez em quando eu pensava em suicídio... se for por aqui (garganta) eu posso ficar tetraplégico se acertar outro lugar... se for por aqui (cabeça) aí é direto. Uma coisa que marcou muito foi o carinho que a psicóloga teve comigo. Eu vi ela dizer pra uma menina que ela era inteligente e que ia dar tudo certo, que não se preocupasse. E depois que ela começou a pegar meu caso tive esperança que pela medicina (setor de medicina do trabalho) eu pudesse ser transferido.

Por fim, ressalte-se que o próprio Ministério da Saúde (2001) reconhece que a relação entre os episódios depressivos e o trabalho pode ser sutil. Entretanto, os episódios depressivos podem de fato estar relacionados a vivências no trabalho, como: "decepções sucessivas em situações de trabalho frustrantes, as perdas acumuladas ao longo dos anos de trabalho, as exigências excessivas de desempenho cada vez maior, no trabalho, geradas pelo excesso de competição..." (Ministério da Saúde, 2001, p. 178).

\section{Considerações}

A análise dos relatos de Thales nos permite levantar a hipótese de uma relação estreita entre o trabalho e distúrbio mental. Reforça essa hipótese o fato de que o próprio entrevistado atribui às experiências de trabalho um papel central na determinação de seu estado de saúde.

As indicações brevemente feitas neste caso fortalecem a necessidade de nos pautarmos em uma abordagem capaz de analisar as articulações entre as condições objetivas e subjetivas de vida e trabalho, e desvendar na sucessão e no encadeamento dos acontecimentos da vida de um indivíduo o sentido com o qual elas se inscrevem em sua história e o afetam. Dessa forma, as contribuições de Louis Le Guillant, psiquiatra francês, um dos principais líderes de um grupo de fundadores da Psicopatologia do Trabalho, representam um avanço nessa direção (Le Guillant, 2006).

A análise do caso de Thales evidencia também a importância de se considerar o trabalho "por dentro", na perspectiva da atividade de trabalho real, reivindicada pela 
Ergonomia da Atividade. Nesse sentido, vale ressaltar que a Ergonomia Francófona tem demonstrado sistematicamente que a "experiência do trabalho real" não equivale ao conjunto de objetivos, normas e procedimentos prescritos por aqueles que concebem o trabalho, isto é, ao "trabalho prescrito" (Guérin, Laville, Daniellou, Duraffourg \& Kerguelen, 2001).

Finalmente, mais do que pensar no "perfil dos indivíduos", como é de costume nas seleções psicológicas, avaliações e nos diagnósticos de trabalhadores, talvez seja preciso lembrar que "antes das pessoas, é do trabalho que é preciso cuidar, em todos os sentidos do termo" (Le Guillant, 1998 citado por Clot, 2008, p. 60, tradução livre).

\section{Referências}

Barros, V. A. \& Silva, L. R. (2002). A pesquisa em história de vida. In Í. GOULART (Org.), Psicologia organizacional e do trabalho: teoria, pesquisa e temas correlatos (pp. 133-146). São Paulo: Casa do Psicólogo.

Clot, Y. (2006). A função psicológica do trabalho. São Paulo: Vozes.

Clot, Y. (2007). Trabalho e sentido do trabalho. In P. Falzon. Ergonomia. São Paulo: Edgar Blucher.

Clot, Y. (2008). Travail e Pouvoir d'agir. Paris: Presses Universitaires.

Dejours, C. (2004). Da psicopatologia à psicodinâmica do trabalho. In S. Lancman \& L. I. Sznelwar (Orgs.), Christophe Dejours: da psicopatologia à psicodinâmica do trabalho. Rio de Janeiro: Fiocruz.

Guerin, F., Laville, A., Daniellou, F., Duraffourg, J. \& kerguelen, A. (2001). Compreender o trabalho para transformálo: a prática da ergonomia. São Paulo: Edgar Blucher.

Jacques, M. G. C. (1997). Identidade e trabalho. In A. D. Cattani (Org.), Trabalho e tecnologia: dicionário crítico (2a Ed.). São Paulo: Vozes.

Le Guillant, L. (2006). Escritos de Louis Le Guillant. São Paulo: Vozes.

Lima, M. E. A. (2002). A questão do método em psicologia do trabalho. In I. B. Goulart (Org.), Psicologia organizacional e do trabalho: teoria, pesquisa e temas correlatos (1를. Ed.). São Paulo: Casa do Psicólogo.

Lima, M. E. A. Assunção, A. Á. \& Francisco, J. M. S. D. (2002). Aprisionado pelos ponteiros de um relógio: o caso de um transtorno mental desencadeado no trabalho. In W. Codo \& M. G. Jacques (Orgs.), Saúde mental $\mathcal{E}$ trabalho: leituras (pp. 209-246). Petrópolis: Vozes.

Marx, K. (1983). Processo de trabalho e processo de valorização. In O capital: crítica da economia política. São Paulo: Abril.

Minayo, M. C. de S. (1993). O desafio do conhecimento: pesquisa qualitativa em saúde (2 $2^{\underline{a}}$ ed.). São Paulo: Hucitec.

Ministério da Saúde. (2001). Doenças relacionadas ao trabalho: manual de procedimentos para os serviços de saúde. Brasília: Ministério da Saúde.

Organização Mundial da Saúde. (1994). CID 10: Classificação Estatística Internacional de Doenças e Problemas Relacionados à Saúde. São Paulo: Edusp.

Politzer, G. (2004). Crítica aos fundamentos da psicologia: a psicanálise e a psicologia (2ª Ed.). Piracicaba: Unimep.

Vieira, C. E. C. (2008). Assédio, do moral ao psicossocial: desvendando os enigmas da organização do trabalho. Juruá: Curitiba.

Vieira, C. E. C. (2009). O nexo causal entre o transtorno de estresse pós-traumático e trabalho: controvérsias acerca do laudo de uma perícia judicial. Revista Brasileira de Saúde Ocupacional, 34, 150-162.

\section{Endereço para correspondência}

carloseduardo_carrusca@yahoo.com.br, rosecarrusca@yahoo.com.br 